\title{
Optical properties of zirconium doped sodium-boro-zinc fluoride glasses
}

Cite as: AIP Conference Proceedings 2115, 030225 (2019); https://doi.org/10.1063/1.5113064

Published Online: 12 July 2019

Roopa, and B. Eraiah

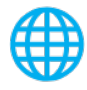

\section{ARTICLES YOU MAY BE INTERESTED IN}

Investigations of optical properties and judd-ofelt analysis of Eu ${ }^{3+}$ ions doped borophosphate glasses

AIP Conference Proceedings 2115, 030235 (2019); https://doi.org/10.1063/1.5113074

\section{Conference Proceedings}

Get $30 \%$ off all print proceedings!
Enter Promotion Code PD/F30 at checkout

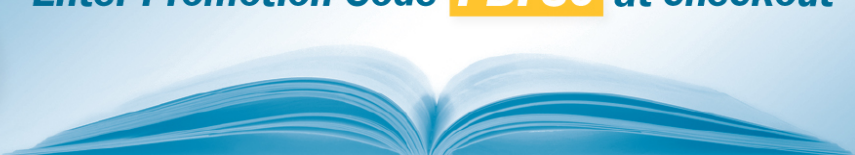




\title{
Optical Properties of Zirconium Doped Sodium-Boro-Zinc fluoride Glasses.
}

\author{
Roopa, B. Eraiah ${ }^{\text {a) }}$ \\ Department of Physics, Bangalore University, Jnana bharathi campus, Bengaluru-560 056, India. \\ a)Email: beraiah@bub.ernet.in, eraiah@rediffmail.com
}

\begin{abstract}
Effect of Zirconium doped sodium borate glasses with zinc fluoride and without zinc fluoride glasses were prepared individually by conventional melt quench method. All the Samples were analyzed using certain measurements like UV-Visible and Photoluminescence. UV-Visible spectra evidences that after $1 \mathrm{~mol} \%$ incorporation to glass matrix there exist ${ }^{3} \mathrm{~F}_{2^{-}}{ }^{3} \mathrm{P}_{1}$ transition due to $\mathrm{Zr}^{2+}$ ions in both $\mathrm{Zr}$ :Zf glass series. Further, using Tauc's equation direct and indirect band gaps were estimated for all samples. Upon the excitation $365 \mathrm{~nm}$ and $383 \mathrm{~nm}$ the PL studies were carried out to know the possible transitions and the role of Zirconium in both glass series for the same CIE diagram was done.
\end{abstract}

\section{INTRODUCTION}

The glass contain oxygen and fluorine much focused in recent years. Introduction of oxide to fluoride increases the rate of crystallization ${ }^{1}$. Addition of fluoride to oxide majorly affects the formation of glass and structure of the glass network, which makes modified laser and optical materials for various technique and scientific applications ${ }^{2,3}$. On the other hand, oxide glass possesses low refractive index, high melting point and high phonon energy. They are highly suitable in designing new optical devices due to their good rare earth ion solubility, easy preparation on large scale shaping and cost effectiveness ${ }^{4}$. Among various transition metal ions, zirconium oxide is one, which acts as good network former and modifier as well ${ }^{5,6}$. Substitution of zirconium oxide along with fluoride to borate glass series represents favourable compromise such as the requirements of low phonon energy, a relatively high thermal stability, high chemical durability, high viscous and ease of fabrication with wide variety of application in photonics 6,7. To the best of our knowledge the optical properties of zirconium oxide containing fluoride glasses have not been discussed thoroughly. In the present paper, we are mainly concentrating to investigate the effect of Zirconium by different concentration on sodium borate glass containing with and without zinc fluoride on some optical properties. Since zirconium as low phonon energy, high refractive index, one can able to expect with wide scope of application in optics and photonics.

\section{EXPERIMENTAL}

In the present discussion, the two glass series $70 \mathrm{~B}_{2} \mathrm{O}_{3}-(\mathrm{x}-30) \mathrm{Na}_{2} \mathrm{O}-\mathrm{xZrO}_{2}$ and $70 \mathrm{~B}_{2} \mathrm{O}_{3}-20 \mathrm{ZnF}_{2}-(\mathrm{x}-30) \mathrm{Na}_{2} \mathrm{O}-\mathrm{xZrO}_{2}(\mathrm{x}$ ranging from 0 to $7 \mathrm{~mol} \%$ ) were prepared by the most common melt quench method. The glass samples are labelled as $\mathrm{Zr0}, \mathrm{Zr} 1, \mathrm{Zr} 3, \mathrm{Zr} 5, \mathrm{Zr} 7$ and $\mathrm{ZF} 0, \mathrm{ZF} 1, \mathrm{ZF} 3, \mathrm{ZF} 5, \mathrm{ZF} 7$ for $0-7 \mathrm{~mol} \% \mathrm{Zr}^{2+}$ ion respectively. Initially AR grade quality compounds $\mathrm{H}_{3} \mathrm{BO}_{4}, \mathrm{Na}_{2} \mathrm{CO}_{3}, \mathrm{ZrO}_{2}$ are used later $\mathrm{ZnF}_{2}$ is also used along with the same series of glass in the fabrication of glasses. Batch calculated compounds with respective gravimetric factor involved were weighed with electronic balance to an accuracy of $0.001 \mathrm{~g}$ and then mixed thoroughly in an agate mortar. The homogeneous mixture taken in a porcelain crucible which was kept in furnace at $1030-1040{ }^{\circ} \mathrm{C}$ for $40 \mathrm{~min}$ till a bubble free liquid was produced. The resultant melt was then transferred on a clean brass slab kept at room temperature to obtain solid pellets of glass samples. The glass samples were annealed for 2 hours at $300{ }^{\circ} \mathrm{C}$ to remove the thermal and 
mechanical stress, then the samples were polished using emery papers for optical measurement. UV-Visible absorption spectra were recorded using a Perkin Elmer Spectrometer in the range of 250 to $800 \mathrm{~nm}$ wavelength. With excitation wavelength $365 \mathrm{~nm}$ and $383 \mathrm{~nm}$, the luminescence spectra of the samples were recorded at room temperature by spectro flouro meter, Horiba Jobin Yvon Fluorolog-3,450W by using Xenon as a source. Luminescence colour of the glass system was categorized by CIE (Commission International de l'Eclairage de France) 1931 chromaticity diagram.

\section{RESULTS AND DISCUSSION}

\section{Absorption spectra analysis}

Figure 1. represents absorption spectra with no sharp absorption peaks are observed in the spectrum of pure sample $\mathrm{Zr} 0$ as it is radical free till $1 \mathrm{~mol} \%$ substitution of $\mathrm{Zr}^{2+}$. At $3 \mathrm{~mol} \%$, $5 \mathrm{~mol} \%$ and $7 \mathrm{~mol} \%$ of $\mathrm{Zr}^{2+}$ the spectra exhibit one intense absorption bands with band positions or peak position at 365,363 and $360 \mathrm{~nm}$ respectively. The peak observed in $3 \mathrm{~mol} \%$ above samples is due to $\mathrm{Zr}^{2+}$ ions $\left({ }^{3} \mathrm{~F}_{2^{-}}{ }^{3} \mathrm{P}_{1}\right.$ transition). The cut off region is 236, 242, 274, 285 and $287 \mathrm{~nm}$ for $0,1,3,5$ and $7 \mathrm{~mol} \%$ of $\mathrm{Zr}^{2+}$. The shift in absorption edge to higher energy confirms the creation of non-bridging oxygen's ${ }^{8,9}$. Later by fixing the $\mathrm{ZnF}_{2}$ concentration to the series of glass for the comparative study of with and without $\mathrm{ZnF}_{2}$ by varying the $\mathrm{Zr}^{2+}$ up to $7 \mathrm{~mol} \%$, there is no sharp absorption peaks are seen in pure $\mathrm{Zf0}$ shown in Fig 2. After 1mol\%, peaks are submerged or absorption peaks are not shown as in the case of $\mathrm{Zr}$ glass series, and due to shift in intensity very small peaks are observed at $381,382,383 \mathrm{~nm}$ for $3 \mathrm{~mol} \%, 5 \mathrm{~mol} \%, 7 \mathrm{~mol} \%$ respectively. This type of intensity takes place because of $\mathrm{Zr}^{2+}$ ion with fluoride content. The cut off region is observed at $326,327,334,313,329 \mathrm{~nm}$ for $1 \mathrm{~mol} \%, 3 \mathrm{~mol} \%, 5 \mathrm{~mol} \%, 7 \mathrm{~mol} \%$ of $\mathrm{Zr}^{2+}$ ion respectively. A non-liner variation observed in the absorption edge and also the ionic radii of $\mathrm{ZnF}_{2}$ is $0.88 \mathrm{~A}^{\circ}$ and the ionic radii of $\mathrm{Zr}^{2+}$ is 0.86 $\mathrm{A}^{\circ}$. The ionic radii of $\mathrm{ZnF}_{2}$ is greater than $\mathrm{Zr}^{2+}$ or it is almost similar, there is no much difference in ionic radii even though which gives the result that fluoride is trying to relocate the $\mathrm{Zr}^{2+}$ ion and trying to reduce the effect of $\mathrm{Zr}^{2+}$ in Zf glass series by submerging the peaks ${ }^{10}$.

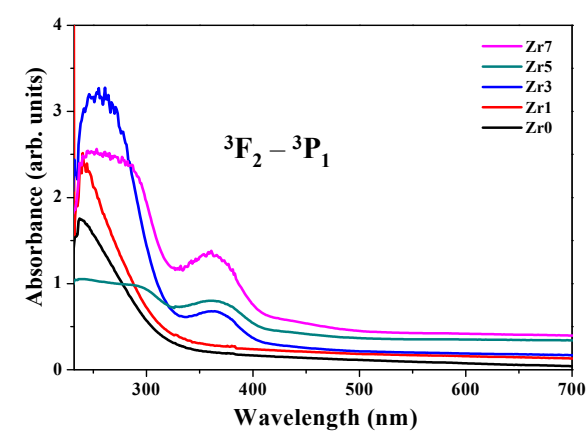

FIGURE 1. Absorption spectra of $\mathrm{Zr}$ glass series

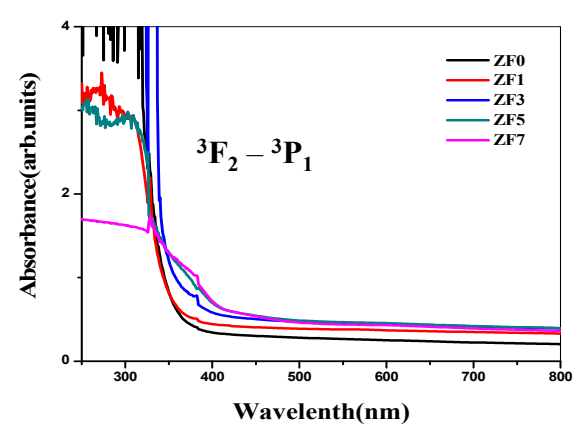

FIGURE 2. Absorption spectra of Zf glass series

Further, the optical absorption coefficient $\alpha(v)$ was calculated for each sample at different photon energies using the relation $\alpha(v)=\mathrm{A} / \mathrm{d}$, where A is the absorbance and $\mathrm{d}$ is the thickness of the glass samples. Using this further optical band gap and Urbach energy will be obtained. The mechanism behind this has explained from the Davis and Mott in two ways ${ }^{11}$, either direct transition $\left((\alpha h v)^{2}\left(\mathrm{~cm}^{-1} \mathrm{eV}\right)^{2} \mathrm{v} / \mathrm{s} \mathrm{E}\right.$ in eV) or indirect transition $\left((\alpha h v)^{1 / 2}\left(\mathrm{~cm}^{-1} \mathrm{eV}\right)^{1 / 2} \mathrm{v} / \mathrm{s} \mathrm{E}\right.$ in $\mathrm{eV})$. The direct and indirect band gap energies were calculated for both $\mathrm{Zr}$ and $\mathrm{Zf}$ glass series, which is observed the same trend that there exist non-linear variations in the values obtained as reported. To calculate the values of Urbach energy, we have plotted logarithm of the absorption coefficient versus photon energy by considering the reciprocals of the slope of linear portion in the lower photon energy region. It was reported that creation of defects in glass network by increasing Urbach energy. Therefore, weak bonds are converted into defects a $\mathrm{Zr}^{2+}$ ions 
concentration is increased in the present glass system. The variation of energy gap is observed in indirect, direct and urbach energies while increasing up to $7 \mathrm{~mol} \%$ of Zirconium content in the host matrix. The non-bridging oxygen ion content increases there by shifting the band edge to lower energies, which in-turn decreases the optical energy band gap energy values and increases the Urbach energy values ${ }^{8,9,12}$. All the energy band gap values of both $\mathrm{Zr}$ and Zf glass series as depicted in Table 1.

TABLE 1. Direct band gap $\left(E_{D i}\right)$, Indirect Band gap $\left(E_{\text {ind }}\right)$ eV, Urbach Energy $\left(E_{U}\right)$ band gap values of Zr: Zf Series

\begin{tabular}{ccccccccccc} 
Sample code & Zr0 & Zr1 & $\mathbf{Z r 3}$ & $\mathbf{Z r 5}$ & $\mathbf{Z r 7}$ & $\mathbf{Z f 0}$ & $\mathbf{Z f 1}$ & $\mathbf{Z f 3}$ & $\mathbf{Z f 5}$ & $\mathbf{Z f 7}$ \\
\hline $\mathrm{E}_{\mathrm{Di}}$ in $\mathrm{eV}$ & 4.11 & 4.0 & 3.96 & 3.57 & 3.72 & 3.61 & 3.61 & 3.66 & 2.43 & 2.85 \\
$\mathrm{E}_{\text {ind }}$ in $\mathrm{eV}$ & 2.65 & 2.79 & 3.18 & 2.89 & 2.84 & 3.08 & 3.00 & 3.10 & 2.11 & 2.06 \\
$\mathrm{E}_{\mathrm{U}}$ in eV & 1.035 & 1.044 & 0.466 & 1.217 & 0.714 & 0.306 & 0.367 & 0.461 & 0.727 & 0.88 \\
\hline
\end{tabular}

\section{Emission spectra and CIE Chromaticity Diagram}

The photoluminescence spectra of $\mathrm{Zr}$ and $\mathrm{Zf}$ glass samples recorded at room temperature at the excitation wavelength corresponding to the transition ${ }^{3} \mathrm{~F}_{2^{-}}{ }^{3} \mathrm{P}_{1}$ due to $\mathrm{Zr}^{2+}$ ions. The spectrum of each glass exhibited a broad emission band peaking in the region 400 to $700 \mathrm{~nm}$. Energy levels which produces red emission at $696 \mathrm{~nm}, 685 \mathrm{~nm}$ and orange emission at 580 to $610 \mathrm{~nm}$ and green emission at 485 to $510 \mathrm{~nm}$. Also there is broad hump in the region 410 to $425 \mathrm{~nm}$ as shown in Fig 3 . This band is identified due to ${ }^{3} \mathrm{P}_{0^{-}}{ }^{3} \mathrm{~F}_{2},{ }^{3} \mathrm{P}_{2}-{ }^{3} \mathrm{P}_{1},{ }^{1} \mathrm{G}_{4^{-}}{ }^{3} \mathrm{~F}_{3},{ }^{1} \mathrm{~d}_{2}{ }^{3} \mathrm{~F}_{3},{ }^{1} \mathrm{~S}_{0^{-}}{ }^{3} \mathrm{~F}_{2}$ transition of $\mathrm{Zr}^{2+}$ ions ${ }^{13}$. Where as in the case of fluoride containing glass series at the excitation wavelength $383 \mathrm{~nm}$, there is a slight shift in wavelength by giving the same number of transition in the range of 400 to $750 \mathrm{~nm}$. It may be due to the effect of fluoride (fluoride containing oxide) which is trying to reduce the effect of zirconium since it is host dependent by shifting in wavelength giving several variations by increasing $\mathrm{Zr}^{2+}$ concentration which we can see in Fig 4.

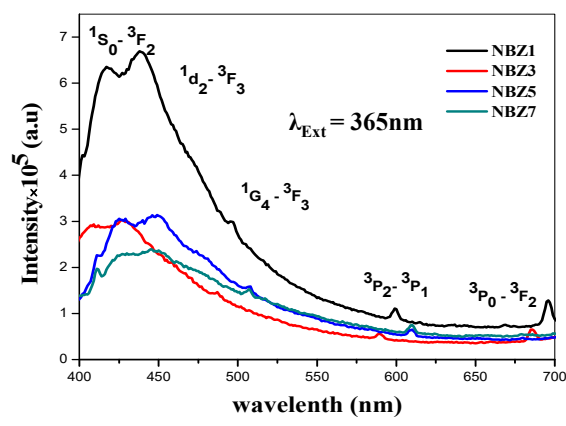

FIGURE 3. Photoluminescence spectra of Zr series

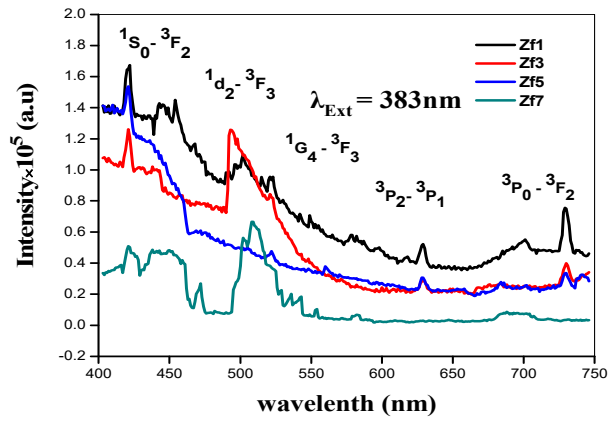

FIGURE 4. Photoluminescence spectra of $\mathrm{Zf}$ series

The colour chromaticity coordinates are evaluated from the emission spectra for different concentrations of Zirconium oxide doped glasses and are represented in the chromaticity diagram as shown in Fig 5 and Fig 6. The coordinates of the emissions for $\mathrm{Zr} 1, \mathrm{Zr} 3 \mathrm{Zr}$, Zr7 glasses excited at $365 \mathrm{~nm}$ are found to be $(0.29,0.29),(0.30,0.30)$ and $(0.22,0.19),(0.29,0.23)$, resulting to be in the blue region, and which are compared to the coordinates of the emissions for Zf1, Zf3, Zf5, Zf7 glasses excited at $383 \mathrm{~nm}$ are found to be $(0.20,0.26),(0.22,0.26)$ and $(0.24,0.21)$, $(0.17,0.23)$ observing blue region. As we can see in both the glass series there is slight shift in blue region. 


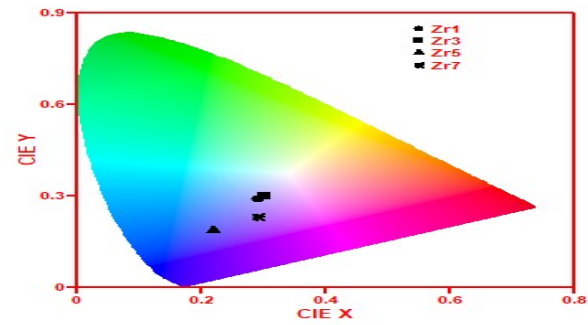

FIGURE 5.CIE Diagram of Zr Glass series.

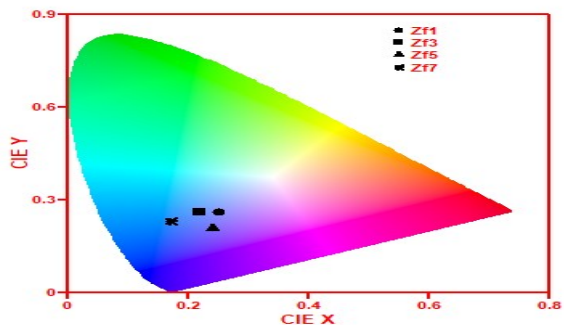

FIGURE 6. CIE Diagram of Zf Glass series.

\section{CONCLUSION}

The effects of Zirconium on the absorption and emissions spectral features of sodium borate glass with and without Zinc fluoride are examined and reported first time. UV-Visible spectra evidences that after $1 \mathrm{~mol} \% \mathrm{ZrO}_{2}$ incorporation to both glass series there exist a ${ }^{3} \mathrm{~F}_{2^{-}}{ }^{3} \mathrm{P}_{1}$ transition due to $\mathrm{Zr}^{2+}$ ions. The peaks are observed at $3 \mathrm{~mol} \%$ in both glass series. And in the case of Zf glass series fluoride is trying to reduce the effect of Zirconium in the glass matrix by submerging the peaks may be due to the higher ionic radii or atomic weight. Red energy shift observed in absorption edge of all glass and energy band gap values evidences that upon incorporating zirconium oxide there exists a formation of non-bridging oxygen's in the present glass matrix. The PL spectra revealed five emission peaks corresponding to the transitions of $\mathrm{Zr}^{2+}$ ion in both glass series among them 365 and $383 \mathrm{~nm}$ are highly intense. The CIE chromaticity diagrams in both the glass series gives the blue emission in visible region. From the above studies suggested that the both glass series are most promising materials for optics and optoelectronic device application.

\section{ACKNOWLEDGMENTS}

One of the Author Roopa, would like to thank UGC-NFSC(RGNF) for providing financial assistance to carry out this research work.

\section{REFERENCES}

1. Amir Reza Hanifi, Annaïk Genson, Wynette Redington, Michael J. Pomeroy, Stuart Hampshire, J. Euro.cer Socity, 32, 849 (2012).

2. B.Deva Prasad Raju, C.Madhukar Reddy, Opt. Mater, 34, 1252 (2012).

3. Jean-Luc Adam, J. Fluorine Chem, 107, 265 (2001).

4. T.Srikumar, M.G.Brik, Ch.Srinivasa Rao, N.Venkataramaiah, Y.Gandhi , N.Veeraiah ,Physica B, 406, 3592 (2011).

5. El Saayed Yousef, Amin El-Adaway, N. El Koshkhany, E.R. Shaaban, J. Phys Chem. Solids, 67, 1649 (2006).

6. G.Venkataiah, C.K Jayasankar, K.Venkata krishnaiah, P.Dharmaiah, N.Vijaya, Opt Mater, 40, 26 (2015).

7. Zahara ashur said Mahrz, M.R. sahar, S.K. Ghoshal, J. Molecular Struct, 1072, 238 (2014).

8. B. Eraiah, Sudha G. Bhat, J. Phy \& Chem of Solids, 68, 581 (2007).

9. V.C. Veeranna Gowda, Physica B, 456, 298 (2015).

10. M.M Kozak, D. Goebel, R. Caspary, W. Kowalsky, J. Non- Cryst Solids 351, 2009 (2005).

11. N F. Mott, E.A. Davis, Philos. Mag. 28, 903 (1970).

12. F Urbach, Phys. Rev. 92,1324 (1953).

13. Rajkumar, atomic molecular spectra: Laser, Meerut.U.P.,2018, pp. 90-100. 